\title{
Inducible expression of phospholipid transfer protein (PLTP) in transgenic mice: acute effects of PLTP on lipoprotein metabolism
}

\author{
Matthijs Moerland · Nora Anghelescu • Hannelore Samyn · Rien van Haperen • \\ Teus van Gent · John Strouboulis · Arie van Tol · Frank Grosveld • \\ Rini de Crom
}

Received: 21 December 2006/Accepted: 19 March 2007/Published online: 17 April 2007

(C) Springer Science+Business Media B.V. 2007

\begin{abstract}
One main determinant in high-density lipoprotein (HDL) metabolism is phospholipid transfer protein (PLTP), a plasma protein that is associated with HDL. In transgenic mice overexpressing human PLTP we found that elevated plasma PLTP levels dose-dependently increased the susceptibility to dietinduced atherosclerosis. This could be mainly due to the fact that most functions of PLTP are potentially atherogenic, such as decreasing plasma HDL levels. To further elucidate the role of PLTP in lipoprotein metabolism and atherosclerosis we generated a novel transgenic mouse model that allows conditional expression of human PLTP. In this mouse model a human PLTP encoding sequence is controlled by a Tet-On system. Upon induction of PLTP expression, our mouse model showed a strongly increased PLTP activity (from $3.0 \pm 0.6$ to $11.4 \pm 2.8 \mathrm{AU}, p<0.001$ ) The increase in PLTP activity resulted in an acute decrease in plasma cholesterol of $33 \%$ and a comparable decrease in phospholipids. The decrease in total
\end{abstract}

M. Moerland · N. Anghelescu · H. Samyn ·

R. van Haperen - T. van Gent · J. Strouboulis .

A. van Tol · F. Grosveld · R. de Crom $(\bowtie)$

Department of Cell Biology and Genetics, Erasmus

University Medical Center, P.O. Box 2040, 3000 CA

Rotterdam, The Netherlands

e-mail: m.decrom@erasmusmc.nl

R. de Crom

Department of Vascular Surgery, Erasmus University

Medical Center, Rotterdam, The Netherlands plasma cholesterol and phospholipids was caused by a $35 \%$ decrease in HDL-cholesterol level and a $41 \%$ decrease in HDL-phospholipid level. These results demonstrate the feasibility of our mouse model to induce an acute elevation of PLTP activity, which is easily reversible. As a direct consequence of an increase in PLTP activity, HDL-cholesterol and HDL-phospholipid levels strongly decrease. Using this mouse model, it will be possible to study the effects of acute elevation of PLTP activity on lipoprotein metabolism and pre-existing atherosclerosis.

Keywords PLTP · Inducible expression - HDL . Cholesterol $\cdot$ Atherosclerosis $\cdot$ Lipoprotein metabolism

\section{Introduction}

Over the last years, in vitro studies and studies in mice showed that phospholipid transfer protein (PLTP) plays several key roles in lipoprotein metabolism. These include the transfer of phospholipids from triglyceride-rich lipoproteins to high-density lipoproteins (HDL) during lipolysis (Tall et al. 1985), the remodeling of HDL-particles (Jauhiainen et al. 1993; Tu et al. 1993), the stimulation of hepatic very low-density lipoprotein (VLDL) secretion (Jiang et al. 2005, 2001; Lie et al. 2002; van Haperen et al. 2002), and the modification of the inflammatory 
and oxidative state of lipoproteins (Jiang et al. 2005; Jiang et al. 2002; Schlitt et al. 2005; Yan et al. 2004; Yang et al. 2003).

Diet studies in different atherosclerosis-prone mouse models showed that PLTP deficiency resulted in a decreased development of atherosclerosis (Jiang et al. 2001). Overexpression of human PLTP in lowdensity lipoprotein receptor (LDLR) deficient mice resulted in a dose-responsive increase in susceptibility to atherosclerosis (van Haperen et al. 2002). Most functions of PLTP are potentially atherogenic: overexpression of human PLTP dose-dependently decreases HDL levels, resulting in a more atherogenic lipoprotein profile (Albers et al. 1996; van Haperen et al. 2002); overexpression of human PLTP stimulates VLDL secretion by the liver (Lie et al. 2002; van Haperen et al. 2002); lipoprotein oxidizability increases following adenoviral overexpression of PLTP in atherosclerosis-prone mice (Jiang et al. 2002; Yang et al. 2003). On the other hand, PLTP has anti-atherogenic potential as well, because it increases the formation of pre $\beta$-HDL, an HDL subfraction that is a very efficient acceptor of cellular cholesterol and therefore an important mediator in reverse cholesterol transport (Jiang et al. 1996; Lie et al. 2001; van Haperen et al. 2000). Apparently, PLTP displays both pro- and anti-atherogenic properties, of which the experimental approaches used so far demonstrate that the net effect is proatherogenic (Desrumaux et al. 2003; Jiang et al. 2001; Lie et al. 2004; van Haperen et al. 2002; Yang et al. 2003). However, it is important to notice that PLTP is a lipid transfer protein and thus very sensitive to changes in lipaemia (Rye et al. 1998). Depending on the metabolic status, the proatherogenic effects of PLTP could outweigh the antiatherogenic effects, or vice versa. A different experimental approach might shed more light on the exact physiological role of PLTP in lipoprotein metabolism and atherogenesis. Therefore, we generated a new mouse model with conditional expression of the human PLTP gene, using the tetracycline-responsive gene system that was developed by using the Escherichia coli tetracycline resistance Tn10 operon (Gossen and Bujard 1992). This mouse model consists of two transgenes. The first transgene is an improved version of the reverse tetracycline transactivator, 2S-M2 [rtTA2S-M2, developed by Urlinger et al. (Urlinger et al. 2000)], under the control of a ubiquitously expressed hnRNP
A2 (heterogeneous nuclear ribonucleoprotein A2) coding sequence. The second transgene is a human PLTP encoding sequence under the transcriptional control of a tetracycline operator and minimal cytomegalovirus promoter (Gossen and Bujard 1992; Orth et al. 2000). The crossbreeding of these two transgenic mouse lines results in a mouse that gives us the opportunity to activate the expression of human PLTP by administration of doxycycline. In the future, using this mouse model, it will be possible to use new and refined approaches studying the physiological role of PLTP. For example, we will be able to investigate the effect of acute elevation of PLTP activity on preexisting atherosclerosis. In this study, we describe the features of our conditional mouse model. Using this model we studied some effects of acute changes in PLTP activity on lipoprotein metabolism.

\section{Methods}

\section{DNA constructs}

Two constructs were used to generate transgenic mice that would allow externally inducible expression of PLTP: (1) hnRNP-rtTA-SV40, which consists of a recent version of the tetracycline-controlled transactivator rtTA2S-M2 (Urlinger et al. 2000) under the control of an hnRNP A2 coding sequence (Antoniou et al. 2003). This sequence consists of an $8 \mathrm{kB}$ methylation-free island, containing the incomplete HP1 $\gamma$ (heterochromatin protein $1 \gamma$ ) promoter, first exon and a part of the first intron of genomic human hnRNP A2, which is expressed ubiquitously (Kamma et al. 1999) (Fig. 1a). (2) TRE-hPLTP, which consists of a human PLTP encoding sequence under the transcriptional control of a Tetracycline Response Element (TRE) containing eight tetracycline operators, and minimal cytomegalovirus promoter $\left(\mathrm{P}_{\text {mincmv }}\right)$ (Gossen and Bujard 1992; Orth et al. 2000) (Fig. 1b). This construct was generated using the pTRE vector (GenBank Accession \#U89931) of ClonTech (ClonTech Laboratories, CA, USA). The human PLTP encoding sequence was constructed from genomic human PLTP, of which the sequences upstream from exon 1 were removed, and the genomic sequences between the Bam $\mathrm{HI}$ sites in exons 5 and 8 were replaced by the equivalent cDNA sequence (264 bp) (Day et al. 1994). 


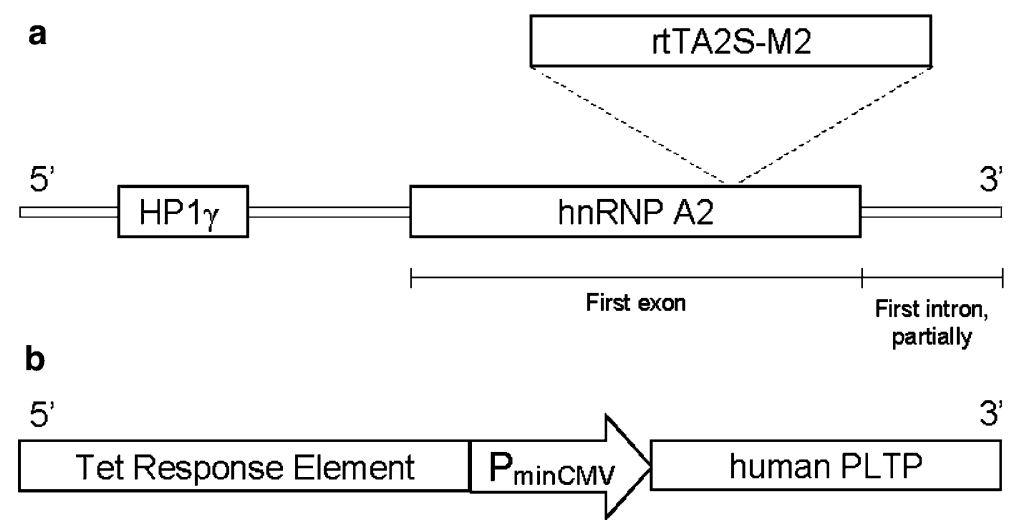

Fig. 1 Schematic diagram showing constructs used for generating transgenic mice. (a) hnRNP-rtTA-SV40, which consists of a tetracycline-controlled transactivator (rtTA2SM2) under the control of an hnRNP A2 coding sequence. This sequence consists of an $8 \mathrm{~kb}$ methylation-free island, containing the incomplete HP1( and promoter, first exon and a part of the first intron of genomic human hnRNP A2. (b) TRE-hPLTP, which consists of a human PLTP encoding sequence under the

Generation and treatment of transgenic mice

For both constructs, vector sequences were removed by restriction endonuclease digestion. Linear DNA was dissolved in microinjection buffer $(10 \mathrm{mmol} / \mathrm{L}$ Tris-HCl, $\mathrm{pH}$ 7.5, $0.1 \mathrm{mM}$ EDTA) at a concentration of $1-2 \mu \mathrm{g} / \mathrm{ml}$. DNA constructs were microinjected into fertilized oocytes from FVB mice. These oocytes were transferred into the oviducts of pseudopregnant foster females. Transgenic founder mice were bred with FVB mice to obtain transgenic mice. FVB transgenic mice were backcrossed with $\mathrm{C} 57 \mathrm{~B} 1 / 6$ mice for at least ten generations. Genotypes were identified by polymerase chain reaction (PCR) using genomic DNA from tail clips of 10-day-old mice. Primers used for the presence of the rtTA transgene: sense $5^{\prime}$-GGA ACA GGA GCA TCA AGT AGC-3', antisense 5'GCG TCA GCA GGC AGC ATA TC-3'; 32 cycles $\left(45 \mathrm{~s} 94^{\circ} \mathrm{C}, 60 \mathrm{~s} 62^{\circ} \mathrm{C}, 90\right.$ s. $72^{\circ} \mathrm{C}$ ). Primers used for the presence of the human PLTP transgene: sense $5^{\prime}$ GCC ACA GCA GGA GCT GAT GC- $3^{\prime}$, antisense 5'-GCG GAT GGA CAC ACC CTC AGC-3'; 32 cycles $\left(45 \mathrm{~s} 94^{\circ} \mathrm{C}, 90 \mathrm{~s} 65^{\circ} \mathrm{C}, 90 \mathrm{~s} 72^{\circ} \mathrm{C}\right)$.

Animals were kept on regular chow. Blood samples were collected from the orbital plexus. Blood was centrifuged at $2,800 \mathrm{rpm}$ for $15 \mathrm{~min}$ at $4^{\circ} \mathrm{C}$. Plasma samples were stored at $-80^{\circ} \mathrm{C}$ until measurement of PLTP activity and quantification of transcriptional control of a Tetracycline Response Element (TRE) and minimal cytomegalovirus promoter. The human PLTP encoding sequence was constructed from genomic human PLTP, of which the sequence upstream from exon 1 was removed, and the genomic sequences between the BamHI sites in exons 5 and 8 were replaced by the equivalent cDNA sequence $(264 \mathrm{bp})$

plasma lipids. All experiments were performed in accordance with institutional and national regulations.

In vivo induction of PLTP activity

Mice carrying the reverse tetracycline transactivator (referred to as rtTAtg mice) were crossed with mice carrying the human PLTP gene under the control of the tetracycline-responsive element (referred to as Tre-PLTPtg mice), resulting in Tre-PLTPtg//rtTAtg mice. As controls, transgenic mice were used having only one of the transgenes, thus either lacking the rtTA transgene, or the Tre-PLTP transgene. Induction of PLTP expression needs addition of doxycycline to the drinking water. In order to mask the bitter taste of doxycycline, 5\% sucrose was added. First, the mice were kept on drinking water containing $5 \%$ sucrose for 3 days, followed by drinking water containing $2 \mathrm{mg} / \mathrm{ml}$ doxycycline hydrochloride (Sigma) $+5 \%$ sucrose for 2 days. Doxycycline-containing drinking water was protected from light. PLTP activity was determined before the sucrose run-in period, after 3 days of sucrose administration and after 2 days of doxycycline administration. In an additional experiment, the turnover of the induced PLTP activity was determined. A group of Tre-PLTPtg//rtTAtg mice was treated according the regime described above, 
followed by a 5-days period of normal drinking water. Every day, a small amount of blood was taken by tail bleeding, starting after the sucrose run-in period of 3 days. In these samples PLTP activity was measured.

\section{PLTP activity assay}

PLTP activity was measured using a phospholipid vesicle-HDL system, according to Speijer et al. (Speijer et al. 1991). PLTP activity is expressed as arbitrary units (AU). One arbitrary unit is equal to the level of PLTP activity found in human reference plasma, which is $13.9 \mu \mathrm{mol} / \mathrm{ml} / \mathrm{h}$.

\section{Separation of lipoproteins}

High-density lipoprotein and non-HDL fractions were separated by density gradient ultracentrifugation of freshly isolated plasma samples using a Beckman $42.2 \mathrm{Ti}$ rotor $\left(42,000 \mathrm{rpm}, 2 \mathrm{~h} 50 \mathrm{~min}, 12^{\circ} \mathrm{C}\right)$ at $d=1.063 \mathrm{~g} / \mathrm{ml}$.

Quantification of plasma lipids

Cholesterol concentration was determined enzymatically using a Free Cholesterol C kit (WAKO) after hydrolysis of cholesteryl esters with cholesterol esterase from Candida cylindracaea (Boehringer). Phospholipid concentration was measured using the PAP150 kit from BioMerieux. Triglycerides were measured using a triglyceride kit from WAKO.

Protein analysis of plasma samples

In order to analyze apoAI protein mass, equal plasma samples of individual mice were subjected to electrophoresis on precast 4-15\% SDS-polyacrylamide gradient gels (Bio-Rad) which were subsequently stained with Coomassie blue (Brilliant Blue R, Sigma).

mRNA expression analysis

Mice were humanely killed and organs were quickly removed and homogenized. Total RNA was isolated using the RNeasy Mini Kit (Qiagen). Isolated RNA was used as a template for reverse transcription primed by oligo(dT). cDNA was used as a template for Real-Time PCR to quantitate RNA expression using the MyIQ (Bio-Rad). Sample cycle threshold $(\mathrm{Ct})$ values were determined from plots of relative fluorescence units versus PCR cycle number during exponential amplification. Relative mRNA levels were normalized to hypoxanthine-guanine phosphoribosyl transferase expression using the $\Delta \mathrm{Ct}$ method $\left[2^{(-\Delta \mathrm{Ct})}\right]$ and presented as arbitrary units. All experiments were repeated three times. Details on the primer sets used and PCR conditions are available upon request via e-mail (m.decrom@erasmusmc.nl).

Statistical analysis

All values are expressed as means \pm standard error of the mean. Statistical analyses were done by one-way analysis of variance with Bonferroni multiple comparison tests or Student's $t$-tests using Intercooled Stata 8.2/SE software (Stata Corporation, College Station, TX, USA).

\section{Results}

Induction of PLTP expression

First, we tested whether inducible expression of human PLTP could be achieved in our newly generated mouse model. To this end, three experimental groups were used: Tre-PLTPtg//rtTAtg mice, Tre-PLTPtg mice and rtTAtg mice. Mice were kept on drinking water containing 5\% sucrose for 3 days prior to doxycycline administration, When the effect of sucrose on plasma PLTP activity and lipid levels was measured, no statistically significant differences in plasma PLTP activity between groups before and after sucrose administration were found (Fig. 2). PLTP activity in the Tre-PLTPtg mice or rtTAtg mice (PLTP activity $2.9 \pm 0.7 \mathrm{AU}$ and $2.8 \pm 0.7 \mathrm{AU}$, respectively) did not differ from the activity in chowfed wildtype mice on normal drinking water (3.3 $\pm 0.8 \mathrm{AU}, n=6$ mice). After 3 days, drinking water containing $5 \%$ sucrose was replaced with drinking water containing $2 \mathrm{mg} / \mathrm{ml}$ doxycycline $+5 \%$ sucrose. After 2 days, plasma PLTP activity was measured. In the Tre-PLTPtg mice and rtTAtg mice, administration of doxycycline had no effect on PLTP 


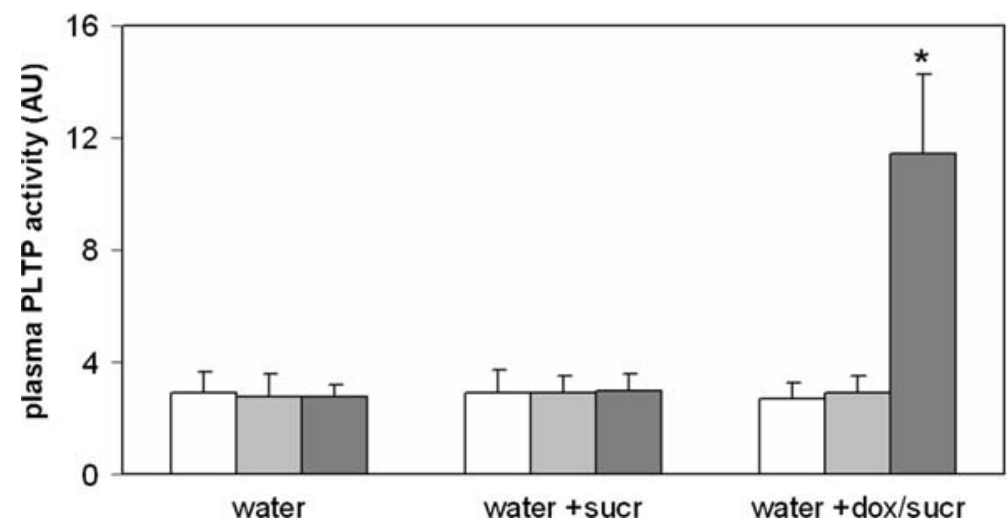

Fig. 2 Plasma PLTP activity levels. PLTP was measured in plasma samples and expressed in arbitrary units (1 AU is equal to the level of PLTP activity found in human reference plasma, $13.9 \mu \mathrm{mol} / \mathrm{ml} / \mathrm{h}$ ). Measurements were performed at three time points: "water" (normal drinking water), "water + sucr" (after 3 days of drinking water containing 5\% sucrose),

activity. However, in the PLTPtg//rtTAtg group administration of doxycycline resulted in a strong increase in PLTP activity (from $3.0 \pm 0.6$ to $11.4 \pm 2.8$ AU, Fig. 2).

Next, the duration of the doxycycline-induced PLTP activity was determined. A group of TrePLTPtg//rtTAtg mice was treated according to the regime described above, followed by a 5 -days period on normal drinking water. During the 2 days of treatment with doxycycline, PLTP activity increased from $2.3 \pm 0.4$ AU to $9.2 \pm 2.2$ AU (Fig. 3). PLTP activity further increased to $9.9 \pm 2.3 \mathrm{AU}$ after 1 day after on normal drinking water and subsequently
' water + dox/sucr', (after 2 days of drinking water containing $2 \mathrm{mg} / \mathrm{ml}$ doxycycline $+5 \%$ sucrose). White bars indicate TrePLTPtg mice, gray bars indicate rtTAtg mice, black bars indicate Tre-PLTPtg//rtTAtg mice. $n=15-18$ mice/group. ${ }^{*} p<0.001$, versus Tre-PLTPtg//rtTAtg + dox/sucr and versus Tre-PLTPtg + sucr and rtTAtg + sucr

started to decline. Five days after discontinuing the doxycycline treatment, PLTP activity had returned to the initial level.

Effects of human PLTP expression on plasma lipids and lipoproteins

Cholesterol and phospholipid levels were measured in plasma to investigate the effects of an acute increase in plasma PLTP activity on lipid metabolism. After administration of doxycycline, there was only a $10 \%$ decrease in plasma cholesterol in one of the control groups, Tre-PLTPtg mice (Fig. 4a, from

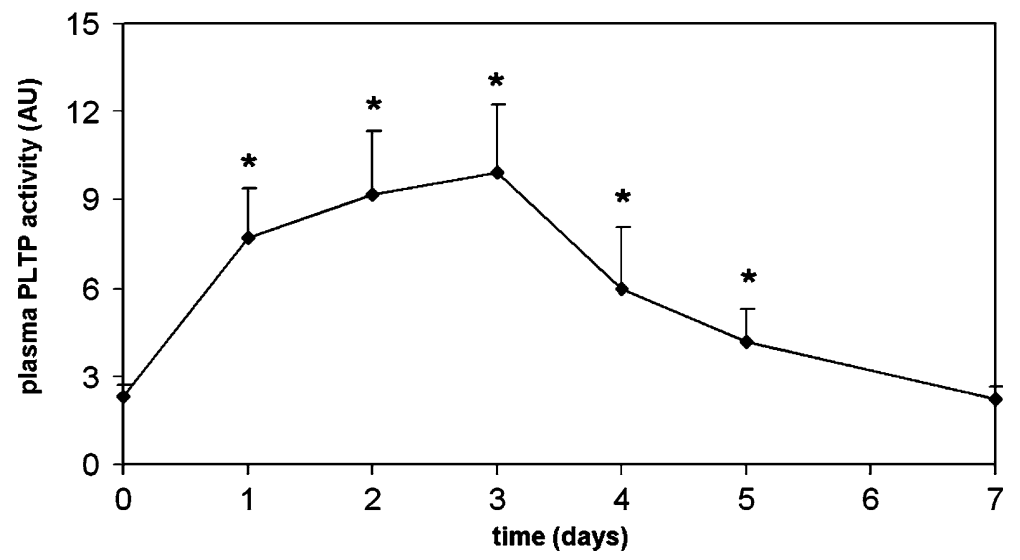

Fig. 3 Plasma PLTP activity levels in Tre-PLTPtg//rtTAtg mice. PLTP was measured in plasma samples and expressed in arbitrary units. Time points of measurement: $t=0$ (after 3 days of drinking water containing 5\% sucrose); $t=1$ and $t=2$ (drinking water containing $2 \mathrm{mg} / \mathrm{ml}$ doxycycline $+5 \%$ sucrose); $t=3, t=4, t=5, t=7$ (normal drinking water). $n=6$ mice. ${ }^{*} p<0.001$ versus $t=0$ 
$2.7 \pm 0.3 \mathrm{mM}$ to $2.5 \pm 0.4 \mathrm{mM}, p<0.02$ ), while plasma cholesterol levels in the other control group, rtTAtg mice, remained unchanged. In the TrePLTPtg//rtTAtg mice however, induction of PLTP expression by doxycycline administration resulted in a $33 \%$ decrease in plasma cholesterol (from $2.7 \pm 0.4 \mathrm{mM}$ to $1.8 \pm 0.6 \mathrm{mM}, p<0.001)$. Plasma phospholipid levels were also lowered after induction of PLTP activity, by $33 \%$ (Fig. 5a, from $2.6 \pm 0.4 \mathrm{mM}$ to $1.7 \pm 0.5 \mathrm{mM}, p<0.001)$. In the control groups, phospholipid levels did not change significantly following administration of doxycycline. Addition of 5\% sucrose to the drinking water had no statistically significant effects on plasma cholesterol or phospholipid levels. Triglyceride levels are very low in chow-fed C57Bl/6 mice. Administration of doxycycline resulted in a decrease in triglyceride levels, both in the control groups (from $0.52 \pm 0.16$ to $0.35 \pm 0.17 \mathrm{mM}$ in Tre-PLTPtg mice, $p<0.001$, and from $0.48 \pm 0.17 \mathrm{mM}$ to $0.35 \pm 0.17 \mathrm{mM}$ in rtTAtg mice, $p<0.001$ ) as well as in the Tre-PLTPtg//rtTAtg mice (from $0.54 \pm 0.19$ to $0.33 \pm 0.17 \mathrm{mM}, p<0.001$ ), indicating that the decrease in plasma triglycerides is not caused by the action of PLTP.

The decreases in plasma cholesterol and phospholipids in the Tre-PLTPtg//rtTAtg mice were studied in more detail. Lipoprotein fractions were separated by ultracentrifugation. In all groups, administration of 5\% sucrose significantly increased total cholesterol and phospholipids in the non-HDL fractions, which remained unchanged after the subsequent addition of doxycycline (Fig. 4c, 5c). Administration of doxycycline $+5 \%$ sucrose had no statistically significant effects on total cholesterol levels or phospholipid levels in the HDL fractions of both control groups (Fig. 4b, 5b). However, in the human PLTP-expressing Tre-PLTPtg//rtTAtg mice, HDL-cholesterol
Fig. 4 Cholesterol levels.

(a) Total plasma cholesterol, (b) HDLcholesterol, (c) non-HDLcholesterol. Measurements were performed at three time points: "water" (normal drinking water), " water + sucr" (after 3 days of drinking water containing $5 \%$ sucrose), "water + dox/sucr" (after 2 days of drinking water containing $2 \mathrm{mg} / \mathrm{ml}$ doxycycline $+5 \%$ sucrose) . White bars indicate TrePLTPtg mice, gray bars indicate rtTAtg mice, black bars indicate Tre-PLTPtg// rtTAtg mice. $n=15-$ 18 mice/group. ${ }^{*} p<0.05$, $* * p<0.001$, versus TrePLTPtg and rtTAtg + dox/ sucr. ${ }^{\#} p<0.001$, versus TrePLTPtg//rtTAtg + sucr. ${ }^{\S} p<0.05$, versus TrePLTPtg and rtTAtg + sucr. ${ }^{\dagger}$ $p<0.01$, each group versus normal drinking water
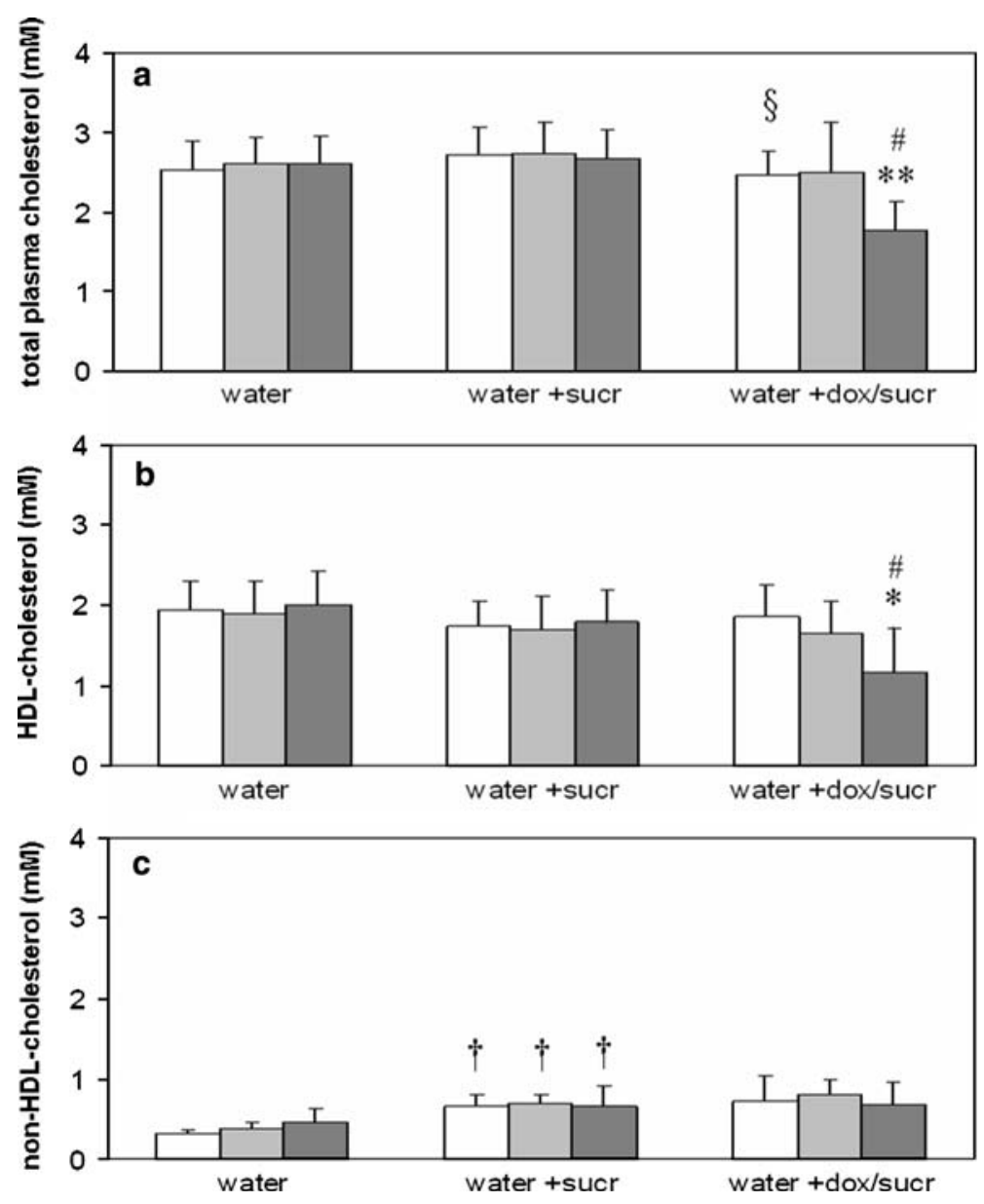
Fig. 5 Phospholipid levels.

(a) Total plasma phospholipids, (b) HDLphospholipids, (c) nonHDL-phospholipids.

Measurements were performed at three time points: "water" (normal drinking water),

"water + sucr" (after 3 days of drinking water containing $5 \%$ sucrose), "water + dox/sucr" (after 2 days of drinking water containing $2 \mathrm{mg} / \mathrm{ml}$ doxycycline $+5 \%$ sucrose) . White bars indicate TrePLTPtg mice, gray bars indicate rtTAtg mice, black bars indicate Tre-PLTPtg// rtTAtg mice. $n=15$ 18 mice/group. $* p<0.001$, versus Tre-PLTPtg and rtTAtg + dox/sucr. ${ }^{\#} p<0.001$, versus TrePLTPtg//rtTAtg + sucr. ${ }^{\S} p<0.01$, each group versus normal drinking water
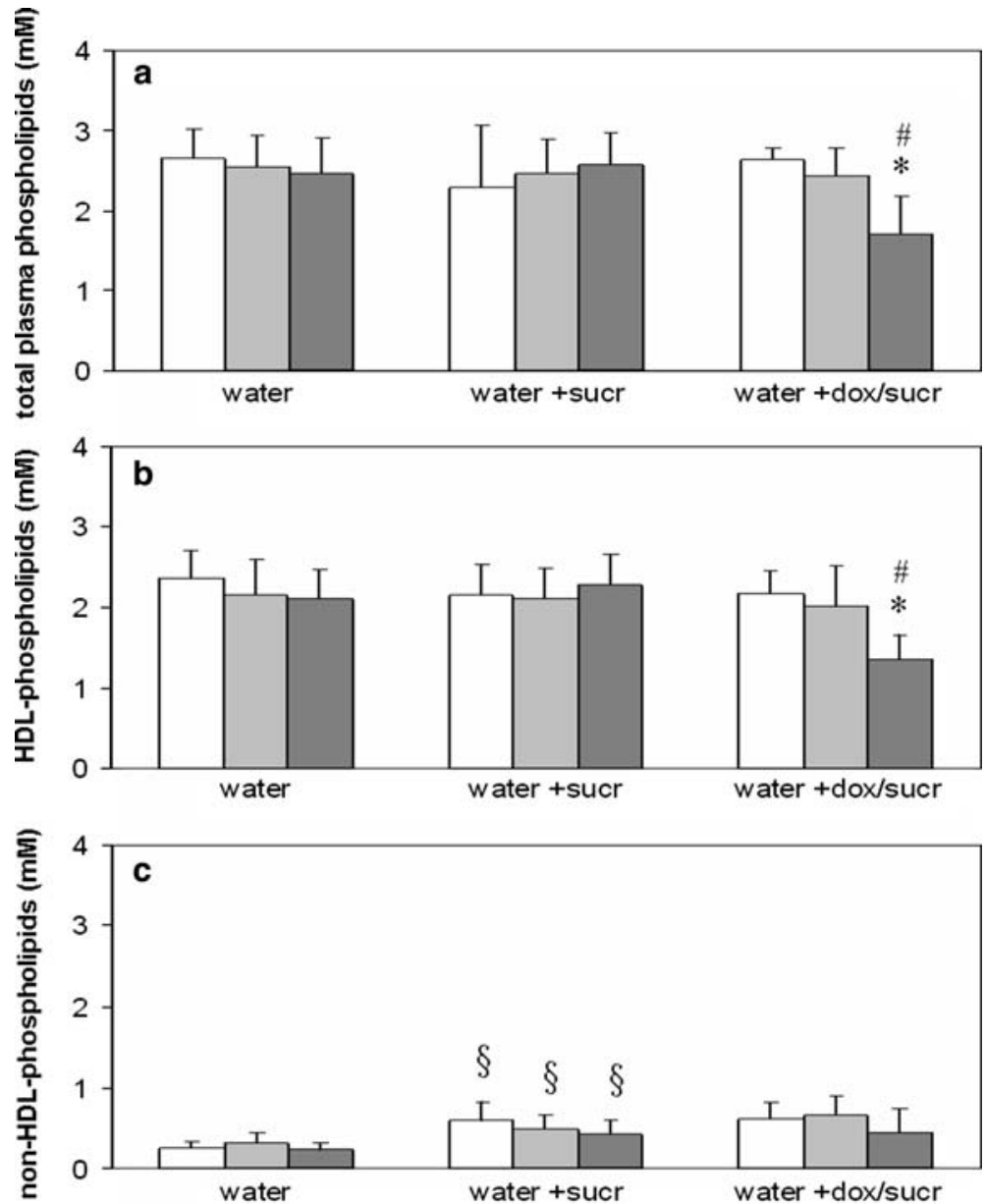

decreased by $35 \%$ (from $1.8 \pm 0.4 \mathrm{mM}$ to $1.2 \pm 0.4 \mathrm{mM}, p<0.001)$, and HDL-phospholipid level decreased by $41 \%$ (from $2.3 \pm 0.4 \mathrm{mM}$ to $1.4 \pm 0.3 \mathrm{mM}, p<0.001)$. Furthermore, plasma apoAI protein level decreased after induction of PLTP expression (Fig. 6).

mRNA expression analysis

Liver rtTA and PLTP mRNA expression levels were measured by Real-Time PCR (Table 1). RNA was isolated from livers of Tre-PLTPtg//rtTAtg mice, Tre-PLTPtg mice and rtTAtg mice that had been treated with doxycycline for 2 days, and from livers of Tre-PLTPtg//rtTAtg mice that had not received doxycycline in the drinking water. rtTAtg mice and the Tre-PLTPtg//rtTAtg mice (with and without doxycycline) showed similar levels of rtTA expression. Induction by doxycycline gave rise to a tenfold increase in PLTP mRNA (human + murine) in the inducible transgenic mouse model compared to Tre-PLTPtg//rtTAtg mice that had not been given doxycycline and therefore expressed only murine PLTP (from $1.5 \pm 0.9$ to $11.7 \pm 2.7 \mathrm{AU}$, $p<0.001)$. In the control groups there were no differences in PLTP expression. Induction of human PLTP expression did not suppress murine PLTP mRNA levels.

In addition, the effect of an acute increase in PLTP activity on RNA expression level of various key players in lipoprotein metabolism was studied (Table 1). Compared to the control groups, induction of PLTP in the double transgenic mice did not result in a statistically significant change in RNA expression level of ATP-binding cassette A1 (ABCA1), apolipoprotein AI (apoAI), apolipoprotein B (apoB) or scavenger receptor class B type I (SRBI). 


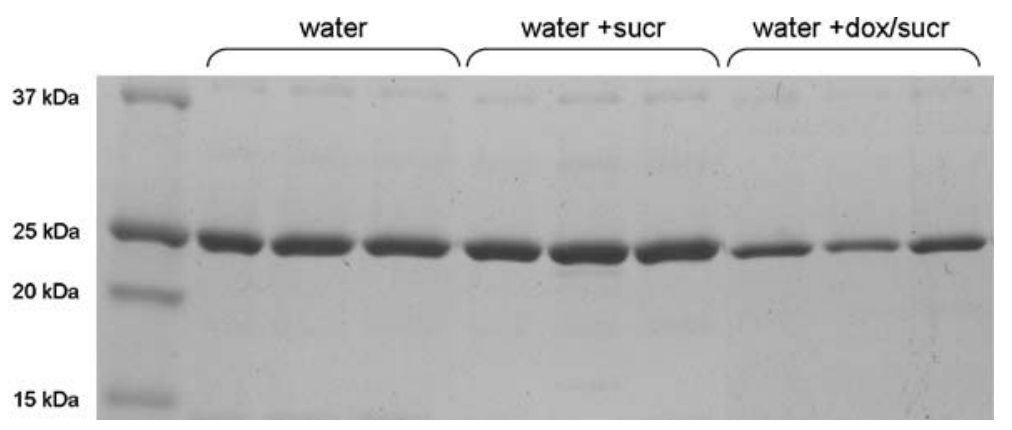

Fig. 6 ApoAI protein mass in individual plasma samples of Tre-PLTPtg//rtTAtg mice, three mice per condition (water, water with sucrose, water with doxycycline and sucrose).
Plasma samples were subjected to electrophoresis on precast 4$15 \%$ SDS-polyacrylamide gradient gels and subsequently stained with Coomassie blue

Table 1 Liver mRNA analysis

\begin{tabular}{|c|c|c|c|c|c|c|c|c|c|}
\hline & & mPLTP & hPLTP & $\mathrm{m}+\mathrm{hPLTP}$ & rtTA & ABCA1 & apoAI & apoB & SRBI \\
\hline Tre-PLTPtg & + dox & $1.2 \pm 0.4$ & $0.0 \pm 0.0^{*}$ & $1.2 \pm 0.4^{*}$ & $0.0 \pm 0.0$ & $1.2 \pm 0.2$ & $0.9 \pm 0.2$ & $0.7 \pm 0.4$ & $1.0 \pm 0.3$ \\
\hline rtTAtg & + dox & $0.9 \pm 0.3$ & $0.0 \pm 0.0^{*}$ & $1.0 \pm 0.2^{*}$ & $0.9 \pm 0.1 * *$ & $0.9 \pm 0.4$ & $0.8 \pm 0.2$ & $1.0 \pm 0.9$ & $1.1 \pm 0.4$ \\
\hline Tre-PLTPtg//rtTAtg & $+\operatorname{dox}$ & $1.2 \pm 0.5$ & $10.5 \pm 2.6$ & $11.7 \pm 2.7$ & $1.0 \pm 0.3 * *$ & $1.2 \pm 0.5$ & $0.7 \pm 0.2$ & $1.0 \pm 0.5$ & $1.2 \pm 0.4$ \\
\hline Tre-PLTPtg//rtTAtg & $-\operatorname{dox}$ & $1.5 \pm 1.0$ & $0.0 \pm 0.0 *$ & $1.5 \pm 0.9^{*}$ & $0.9 \pm 0.1 * *$ & $0.9 \pm 0.1$ & $0.8 \pm 0.1$ & $0.5 \pm 0.1$ & $1.0 \pm 0.1$ \\
\hline
\end{tabular}

$* p<0.001$, versus Tre-PLTPtg//rtTAtg + dox

$* p<0.001$, versus Tre-PLTPtg + dox

In another experiment, tissue distribution of murine and human PLTP mRNA was determined in a group of four doxycycline-treated Tre-PLTPtg// rtTAtg mice by Real-Time PCR. Murine PLTP mRNA was mostly present in lung tissue, followed by liver, adipose tissue, brain and heart (Fig. 7a). Lower levels of murine PLTP mRNA were found in adrenals, spleen and kidney. Upon doxycyclineinduction, human PLTP expression appeared to be strongest in liver, lung and kidney (Fig. 7b). Low levels of human PLTP mRNA were detected in spleen, heart, adrenal and adipose tissue. Only negligible amounts of human PLTP mRNA were detected in brain.

\section{Discussion}

In the present study, we describe a mouse model with conditional induction of human PLTP expression: 2 days of doxycycline administration resulted in a strong increase in plasma PLTP activity. The induction of PLTP activity not only proved to be fast, but also transient. Discontinuation of doxycycline admin- istration via the drinking water resulted in a decline of PLTP activity to basal activity levels after 5 days. Upon induction, PLTP mRNA level in the liver increased by tenfold, while in the control groups (Tre-PLTPtg and rtTAtg) plasma PLTP activity and PLTP liver mRNA did not increase. The non-induced double transgenic mouse line (Tre-PLTPtg//rtTAtg without doxycycline) did not show any significant differences in RNA expression compared with control mice, so our inducible mouse model does not show any intrinsic background activity ("leakage") in the non-induced state. The improved version of the tetracycline-controlled transactivator we used (rtTA2S-M2) has been reported to have a low background activity (Lamartina et al. 2002, 2003; Salucci et al. 2002). Our inducible mouse model shows a broad pattern of human PLTP expression (liver, kidney $>$ lung $>$ spleen, heart, adrenal, adipose tissue). It is not known whether this is a reflection of the normal regulation of PLTP expression found in human tissues (Day et al. 1994), a reflection of the doxycycline distribution among tissues (Michel et al. 1984), or a combination of both. The high human PLTP expression levels in liver and kidney might be 
Fig. 7 mRNA expression levels. (a) Tissue distribution of murine PLTP mRNA expression, (b)

Tissue distribution of human PLTP mRNA expression. Tissues were isolated from Tre-PLTPtg// rtTAtg mice supplied with drinking water containing $2 \mathrm{mg} / \mathrm{ml}$ doxycycline $+5 \%$ sucrose for 2 days and subsequently sacrificed $(n=4)$. mRNA levels were normalized to hypoxanthine-guanine phosphoribosyl transferase expression using the $(\mathrm{Ct}$ method $\left(2^{[-\Delta \mathrm{Ct}]}\right)$ and presented as arbitrary units
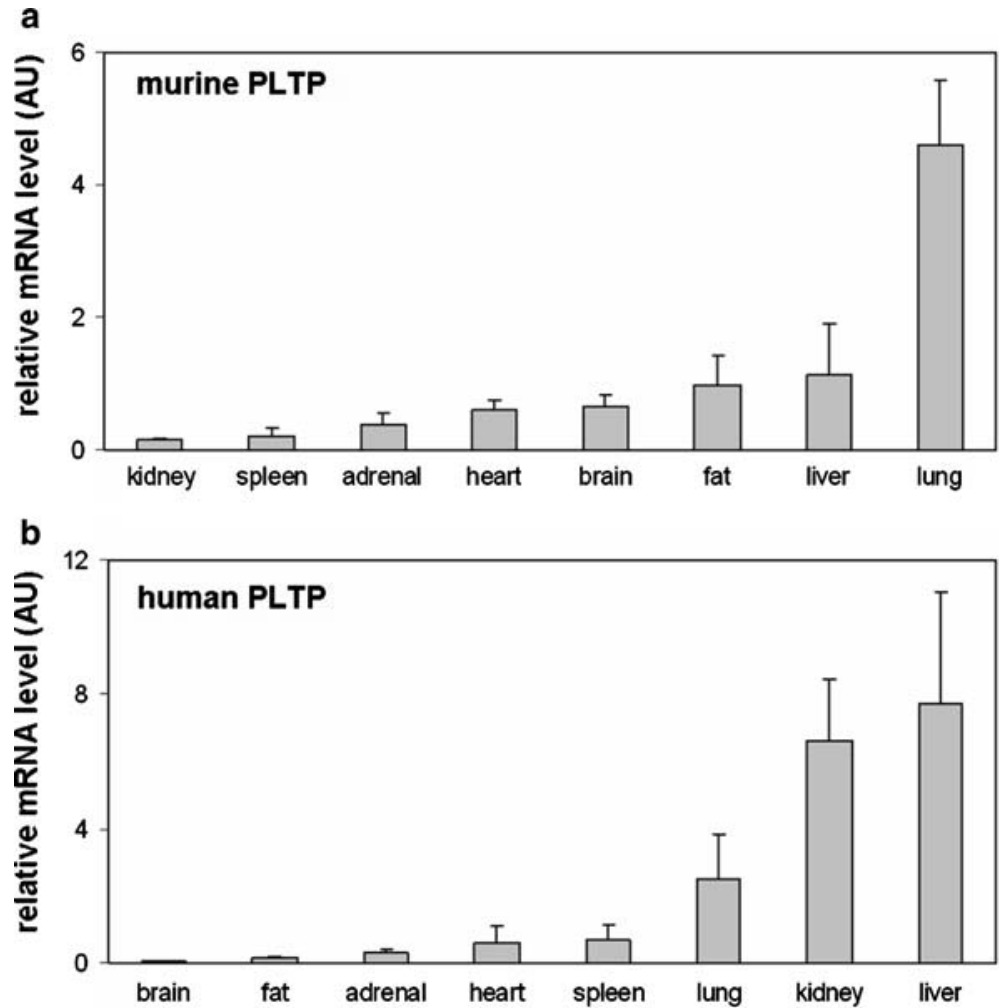

explained by doxycycline distribution between tissues: after oral doxycycline administration to rats, highest levels were measured in excretory organs (i.e., liver and kidney) (Michel et al. 1984). No human PLTP mRNA was detected in brain tissue, probably because doxycycline poorly crosses the blood brain barrier (Michel et al. 1984). The distribution pattern of murine PLTP in human PLTP expressing PLTPtg//rtTAtg mice is comparable with the pattern found in C57BL/6 wildtype mice (Jiang and Bruce 1995).

The increase in PLTP activity in the double transgenic mice resulted in a decrease in plasma cholesterol of $33 \%$ and a comparable decrease in plasma phospholipids. These effects are explained by a decrease in HDL-cholesterol of $35 \%$ and in HDLphospholipids of $41 \%$. These results are well comparable with our previous studies in human PLTP transgenic mice, in which a 2.5- to 4.5-fold increase in PLTP activity in plasma resulted in a $30-40 \%$ decrease in plasma levels of HDL-cholesterol (van Haperen et al. 2000). Concomitantly with the decrease in plasma HDL level, plasma apoAI protein level decreased. This is probably caused by a PLTP- induced increase in HDL catabolism (Föger et al. 1997). In addition, PLTP has been reported to cause proteolytic cleavage of apoAI (Jauhiainen et al. 1999). The decrease in HDL levels cannot be explained by changes in expression of SRBI, apoB or ABCA1. Compared to the control groups, induction of PLTP in the double transgenic mice did not result in statistical changes of mRNA expression levels of these genes. Therefore, the decline in HDL is probably a direct effect of PLTP.

Acute elevation of plasma PLTP activity has been studied before using adenovirus-mediated overexpression of human PLTP (Ehnholm et al. 1998; Föger et al. 1997; Yang et al. 2003). As in our inducible mouse model, also in these studies an increase in PLTP activity resulted in an acute decrease in HDLcholesterol and HDL-phospholipids. An advantage of the inducible mouse model is that it provides a stable and controlled elevation of PLTP activity, which differs from the transient induction obtained by using an adenoviral transfection system. Another important feature of our mouse model is the efficacy to induce PLTP activity, which only requires the administration of doxycycline to the drinking water. We are well 
aware of the fact that long-term administration of high doses of doxycycline might disturb intestinal flora (Riond and Riviere 1988), resulting in diarrhea and colitis. However, the doxycycline dose used in our present study was relatively low and symptoms pointing to a disturbed intestinal flora were not observed. In future experiments, it will be possible to further decrease the doxycycline dose, as maximal induction of PLTP activity was already reached at a dose of $0.25 \mathrm{mg} / \mathrm{ml}$ (data not shown). Recently, the 2S-M2-version of the tetracycline-controlled transactivator has been used in a mouse model that allowed Cre-mediated tetracycline-dependent gene expression in specific embryonic tissues ( $Y u$ et al. 2005), and in two mouse models with inducible and tissue-specific gene expression in the neuronal system of adult mice (Kerrison et al. 2005; Michalon et al. 2005). To the best of our knowledge, the present study is the first one to describe an inducible mouse model in the field of cardiovascular research.

In conclusion, the results of our study demonstrate the feasibility of our mouse model to induce an acute elevation of PLTP activity, which is easily reversible. Using this mouse model, it will be possible to study the effects of acute elevation of PLTP activity on lipoprotein metabolism and pre-existing atherosclerosis.

Acknowledgments The authors would like to thank Dr M. Antoniou (Guys Hospital, London, England) for providing us the hnRNP A2 coding sequence and Dr H. Bujard (Universität Heidelberg, Germany) for providing us the transactivator rtTA2S-M2. Part of this work was supported by Zorgonderzoek Nederland Medische Wetenschappen-the Dutch Organisation for Health Research and Development (910-31-806).

\section{References}

Albers JJ, Tu AY, Paigen B, Chen H, Cheung MC, Marcovina SM (1996) Transgenic mice expressing human phospholipid transfer protein have increased HDL/non-HDL cholesterol ratio. Int J Clin Lab Res 26:262-267

Antoniou M, Harland L, Mustoe T, Williams S, Holdstock J, Yague E, Mulcahy T, Griffiths M, Edwards S, Ioannou PA, Mountain A, Crombie R (2003) Transgenes encompassing dual-promoter $\mathrm{CpG}$ islands from the human TBP and HNRPA2B1 loci are resistant to heterochromatinmediated silencing. Genomics 82:269-279

Day JR, Albers JJ, Lofton-Day CE, Gilbert TL, Ching AF, Grant FJ, O'Hara PJ, Marcovina SM, Adolphson JL (1994) Complete cDNA encoding human phospholipid transfer protein from human endothelial cells. J Biol Chem 269:9388-9391

Desrumaux CM, Mak PA, Boisvert WA, Masson D, Stupack D, Jauhiainen M, Ehnholm C, Curtiss LK (2003) Phospholipid transfer protein is present in human atherosclerotic lesions and is expressed by macrophages and foam cells. J Lipid Res 44:1453-1461

Ehnholm S, van Dijk KW, van't Hof B, van der Zee A, Olkkonen VM, Jauhiainen M, Hofker M, Havekes L, Ehnholm C (1998) Adenovirus mediated overexpression of human phospholipid transfer protein alters plasma HDL levels in mice. J Lipid Res 39:1248-1253

Föger B, Santamarina-Fojo S, Shamburek RD, Parrot CL, Talley GD, Brewer HB Jr (1997) Plasma phospholipid transfer protein. Adenovirus-mediated overexpression in mice leads to decreased plasma high density lipoprotein (HDL) and enhanced hepatic uptake of phospholipids and cholesteryl esters from HDL. J Biol Chem 272:2739327400

Gossen M, Bujard H (1992) Tight control of gene expression in mammalian cells by tetracycline-responsive promoters. Proc Natl Acad Sci USA 89:5547-5551

Jauhiainen M, Metso J, Pahlman R, Blomqvist S, van Tol A, Ehnholm C (1993) Human plasma phospholipid transfer protein causes high density lipoprotein conversion. J Biol Chem 268:4032-4036

Jauhiainen M, Huuskonen J, Baumann M, Metso J, Oka T, Egashira T, Hattori H, Olkkonen VM, Ehnholm C (1999) Phospholipid transfer protein (PLTP) causes proteolytic cleavage of apolipoprotein A-I. J Lipid Res 40:654-664

Jiang XC, Bruce C (1995) Regulation of murine plasma phospholipid transfer protein activity and mRNA levels by lipopolysaccharide and high cholesterol diet. J Biol Chem 270:17133-17138

Jiang X, Francone OL, Bruce C, Milne R, Mar J, Walsh A, Breslow JL, Tall AR (1996) Increased prebeta-high density lipoprotein, apolipoprotein AI, and phospholipid in mice expressing the human phospholipid transfer protein and human apolipoprotein AI transgenes. J Clin Invest 98:2373-2380

Jiang XC, Qin S, Qiao C, Kawano K, Lin M, Skold A, Xiao X, Tall AR (2001) Apolipoprotein B secretion and atherosclerosis are decreased in mice with phospholipid-transfer protein deficiency. Nat Med 7:847-852

Jiang XC, Tall AR, Qin S, Lin M, Schneider M, Lalanne F, Deckert V, Desrumaux C, Athias A, Witztum JL, Lagrost L (2002) Phospholipid transfer protein deficiency protects circulating lipoproteins from oxidation due to the enhanced accumulation of vitamin E. J Biol Chem 277:31850-31856

Jiang XC, Li Z, Liu R, Yang XP, Pan M, Lagrost L, Fisher EA, Williams KJ (2005) Phospholipid transfer protein deficiency impairs apolipoprotein-B secretion from hepatocytes by stimulating a proteolytic pathway through a relative deficiency of vitamin $\mathrm{E}$ and an increase in intracellular oxidants. J Biol Chem 280:18336-18340

Kamma H, Horiguchi H, Wan L, Matsui M, Fujiwara M, Fujimoto M, Yazawa T, Dreyfuss G (1999) Molecular characterization of the hnRNP A2/B1 proteins: tissuespecific expression and novel isoforms. Exp Cell Res 246:399-411 
Kerrison JB, Duh EJ, Yu Y, Otteson DC, Zack DJ (2005) A system for inducible gene expression in retinal ganglion cells. Invest Ophthalmol Vis Sci 46:29322939

Lamartina S, Roscilli G, Rinaudo CD, Sporeno E, Silvi L, Hillen W, Bujard H, Cortese R, Ciliberto G, Toniatti C (2002) Stringent control of gene expression in vivo by using novel doxycycline-dependent trans-activators. Hum Gene Ther 13:199-210

Lamartina S, Silvi L, Roscilli G, Casimiro D, Simon AJ, Davies ME, Shiver JW, Rinaudo CD, Zampaglione I, Fattori E, Colloca S, Gonzalez Paz O, Laufer R, Bujard H, Cortese R, Ciliberto G, Toniatti C (2003) Construction of an $\operatorname{rtTA} 2(\mathrm{~s})-\mathrm{m} 2 / \mathrm{tts}(\mathrm{kid})-$ based transcription regulatory switch that displays no basal activity, good inducibility, and high responsiveness to doxycycline in mice and nonhuman primates. Mol Ther 7:271-280

Lie J, de Crom R, Jauhiainen M, van Gent T, van Haperen R, Scheek L, Jansen H, Ehnholm C, van Tol A (2001) Evaluation of phospholipid transfer protein and cholesteryl ester transfer protein as contributors to the generation of pre beta-high-density lipoproteins. Biochem J 360:379385

Lie J, de Crom R, van Gent T, van Haperen R, Scheek L, Lankhuizen I, van Tol A (2002) Elevation of plasma phospholipid transfer protein in transgenic mice increases VLDL secretion. J Lipid Res 43:1875-1880

Lie J, de Crom R, van Gent T, van Haperen R, Scheek L, Sadeghi-Niaraki F, van Tol A (2004) Elevation of plasma phospholipid transfer protein increases the risk of atherosclerosis despite lower apolipoprotein B-containing lipoproteins. J Lipid Res 45:805-811

Michalon A, Koshibu K, Baumgartel K, Spirig DH, Mansuy IM (2005) Inducible and neuron-specific gene expression in the adult mouse brain with the rtTA2S-M2 system. Genesis 43:205-212

Michel G, Mosser J, Olle J (1984) Pharmacokinetics and tissue localization of doxycycline polyphosphate and doxycycline hydrochloride in the rat. Eur J Drug Metab Pharmacokinet 9:149-153

Orth P, Schnappinger D, Hillen W, Saenger W, Hinrichs W (2000) Structural basis of gene regulation by the tetracycline inducible Tet repressor-operator system. Nat Struct Biol 7:215-219

Riond JL, Riviere JE (1988) Pharmacology and toxicology of doxycycline. Vet Hum Toxicol 30:431-443

Rye KA, Jauhiainen M, Barter PJ, Ehnholm C (1998) Triglyceride-enrichment of high density lipoproteins enhances their remodelling by phospholipid transfer protein. J Lipid Res 39:613-622
Salucci V, Scarito A, Aurisicchio L, Lamartina S, Nicolaus G, Giampaoli S, Gonzalez-Paz O, Toniatti C, Bujard H, Hillen W, Ciliberto G, Palombo F (2002) Tight control of gene expression by a helper-dependent adenovirus vector carrying the rtTA2(s)-M2 tetracycline transactivator and repressor system. Gene Ther 9:1415-1421

Schlitt A, Liu J, Yan D, Mondragon-Escorpizo M, Norin AJ, Jiang XC (2005) Anti-inflammatory effects of phospholipid transfer protein (PLTP) deficiency in mice. Biochim Biophys Acta 1733:187-191

Speijer H, Groener JE, van Ramshorst E, van Tol A (1991) Different locations of cholesteryl ester transfer protein and phospholipid transfer protein activities in plasma. Atherosclerosis 90:159-168

Tall AR, Krumholz S, Olivecrona T, Deckelbaum RJ (1985) Plasma phospholipid transfer protein enhances transfer and exchange of phospholipids between very low density lipoproteins and high density lipoproteins during lipolysis. J Lipid Res 26:842-851

Tu AY, Nishida HI, Nishida T (1993) High density lipoprotein conversion mediated by human plasma phospholipid transfer protein. J Biol Chem 268:23098-23105

Urlinger S, Baron U, Thellmann M, Hasan MT, Bujard H, Hillen W (2000) Exploring the sequence space for tetracycline-dependent transcriptional activators: novel mutations yield expanded range and sensitivity. Proc Natl Acad Sci USA 97:7963-968

van Haperen R, van Tol A, Vermeulen P, Jauhiainen M, van Gent T, van den Berg P, Ehnholm S, Grosveld F, van der Kamp A, de Crom R (2000) Human plasma phospholipid transfer protein increases the antiatherogenic potential of high density lipoproteins in transgenic mice. Arterioscler Thromb Vasc Biol 20:1082-1088

van Haperen R, van Tol A, van Gent T, Scheek L, Visser P, van der Kamp A, Grosveld F, de Crom R (2002) Increased risk of atherosclerosis by elevated plasma levels of phospholipid transfer protein. J Biol Chem 277:48938-48943

Yan D, Navab M, Bruce C, Fogelman AM, Jiang XC (2004) PLTP deficiency improves the anti-inflammatory properties of HDL and reduces the ability of LDL to induce monocyte chemotactic activity. J Lipid Res 45:1852-1858

Yang XP, Yan D, Qiao C, Liu RJ, Chen JG, Li J, Schneider M, Lagrost L, Xiao X, Jiang XC (2003) Increased atherosclerotic lesions in apoE mice with plasma phospholipid transfer protein overexpression. Arterioscler Thromb Vasc Biol 23:1601-1607

Yu HM, Liu B, Chiu SY, Costantini F, Hsu W (2005) Development of a unique system for spatiotemporal and lineage-specific gene expression in mice. Proc Natl Acad Sci USA 102:8615-8620 